\title{
A produção científica no Programa de Pós-Graduação Stricto Sensu em Gerontologia da Universidade Católica de Brasília nos seus 12 anos de existência
}

\section{Scientific production in Pos-Graduated Stricto Sensu Gerontology Programme at Catholic University of Brasilia in its 12 years of existence}

\author{
Vicente Paulo Alves ${ }^{a}$, Lucy Gomes ${ }^{b}$, Gisele Soares Mendesc, Maíra de Oliveira Valadares ${ }^{\mathrm{d} *}$ \\ a Doutor em Ciências da Religião, coordenador e professor do Programa de Pós-Graduação Stricto Sensu em Gerontologia da Universidade Católica de Brasília. \\ <vicerap@gmail.com> \\ b Doutora em Fisiologia, professora do Programa de Pós-Graduação Stricto Sensu em Gerontologia da Universidade Católica de Brasília. \\ <lucygomes2006@hotmail.com> \\ Mestre em Gerontologia, Programa de Pós-Graduação Stricto Sensu em Gerontologia da Universidade Católica de Brasília. \\ <gsmendes.fisio@gmail.com> \\ Mestre em Gerontologia pelo Programa de Pós-Graduação Stricto Sensu em Gerontologia da Universidade Católica de Brasília. \\ <mairavaladares@gmail.com>
}

\section{ARTICLE INFO}

\section{Article history}

Received: 29/05/2015

Accepted: 22/06/2015

\section{Correspondent Author}

Vicente Paulo Alves

SQB - Quadra 2, Bloco H, apto. 403

71009-050 Brasília, DF, Brasil

$<$ vicerap@gmail.com>

\section{(C) 2014 All rights reserved}

Editors

Alfredo Cataldo Neto

Irenio Gomes

\begin{abstract}
RESUMO
Objetivos: Investigar a produção científica desenvolvida no âmbito do Programa de Pós-Graduação Stricto Sensu em Gerontologia (PPGG) da Universidade Católica de Brasília (UCB), realizada por seus docentes e discentes, desde a criação do Programa (2003) até 2014. Métodos: Documental, com consulta aos arquivos da Secretaria Acadêmica da Pós-Graduação da UCB utilizando-se os dados oficiais informados à CAPES anvalmente, mediante o Coleta (até o ano de 2012) e a Plataforma Sucupira (a partir de 2013). Resultados: Encontraram-se 193 dissertações defendidas no período 2004-2014, que se transformaram em 1.102 produções bibliográficas dos discentes, entre publicações em revistas, livros, capítulos e apresentações de trabalhos, entre outras, com média acima de 100 produções anuais. Dos docentes foram 1.774 produções, com média anual acima de 161 produções. Conclusões: Foi alcançado um grande número de publicações no Programa. Esforço contínuo deve ser realizado, conjuntamente entre os docentes e discentes, para que se atinja cada vez maior qualidade das publicações, divulgando-as em periódicos de nível A no Qualis CAPES, de forma a contribuir significativamente com a expansão do conhecimento na área da Gerontologia no Brasil. DeSCRITORES: Envelhecimento; Gerontologia; Pós-Graduação Stricto Sensu; Produção científica.
\end{abstract}

\begin{abstract}
Objetives: Investigate the scientific production developed under the Post-Graduated Stricto Sensu Program in Gerontology (PPGG) at the Catholic University of Brasilia (UCB), taking into account teachers and students, since the program's creation (2003) until 2014. Methods: Documentary, with consultation to the archives of the Academic Secretary of the Post-Graduation at UCB, taking the data reported to the annual CAPES through the Coleta (by the year 2012) and the Sucupira platform (from 2013). Results: 193 dissertations were defended in the period 2004-2014, which turned into 1,102 bibliographic productions, including publications in periodics, books, chapters and work presentations, among others, averaging more than 100 annual productions. The teachers were productions of 1774, with an annual average above 161 productions. Conclusions: The program has been reached large number of publications. Continuous effort should be made, jointly between teachers and students, in order to reach increasingly higher quality publications, disseminating them in journals classified as A in the Qualis CAPES, in order to significantly contribute to the expansion of knowledge in the field of Brazil's Gerontology. KEYwORDS: Aging; Gerontology; Post-Graduate Stricto Sensu; Scientific production.
\end{abstract}

\footnotetext{
* Contribuições dos autores: Vicente Paulo Alves - ideia original, estruturação do artigo e correção final; Lucy Gomes - ideia original, dados históricos e revisão do texto; Gisele Soares Mendes - dados complementares, informações dos alunos; Maíra de Oliveira Valadares - confecção das figuras, dados principais e informações dos alunos.
} 


\section{INTRODUÇÃO}

O Programa de Pós-Graduação Stricto Sensu de Gerontologia (PPGG) da Universidade Católica de Brasília (UCB) iniciou suas atividades no primeiro semestre de 2003, sendo aprovado pela Coordenação de Aperfeiçoamento de Pessoal de Nível Superior (CAPES) em dezembro de 2004, com a nota 3. Logo a seguir, no processo de avaliação trienal 2004-2006 recebeu a nota 4 , que foi mantida nos triênios avaliativos seguintes. O Programa representa a realização de antiga aspiração, concretizada num momento de singular oportunidade quando a instituição, desejosa de crescer para melhor servir à comunidade e ao País, reuniu as condições essenciais ao estabelecimento de um curso de alto nível na área do envelhecimento humano. A sua implementação deveu-se, também, à localização geográfica da UCB no Distrito Federal (DF), onde ainda há grande carência de formação em Pós-Graduação ligada à área. O Programa foi também uma resposta às políticas de incentivo da CAPES para ampliação da oferta de formação pós-graduada em todo o País, em particular nas regiões de menor densidade de Programas do gênero, como é o caso da Região CentroOeste do Brasil, e que possuíssem vocação de atrair candidatos das demais regiões geográficas, como do Norte e Nordeste.

Desde o início de seu funcionamento, o Programa foi reconhecido por qualidade de suas Linhas de Pesquisa ("Aspectos Físicos e Biológicos Relacionados ao Envelhecimento" e "Aspectos Sócio-Psico-Culturais do Envelhecimento"), por seu corpo docente qualificado e pelo bom índice de produtividade e publicações científicas ${ }^{1}$. Seus objetivos foram formar profissionais reflexivos e criativos, agentes transformadores do mundo, de si próprios e dos outros homens, sujeitos de sua história e abertos à vida comunitária e ao diálogo, prestando cuidados profissionais e humanísticos à população geral e, em especial, à população idosa, ajudando a consolidar a cidadania e, assim, possibilitando a construção de uma sociedade brasileira mais justa e fraterna. $\mathrm{O}$ profissional que se quer formar deve estar sintonizado com as necessidades da sociedade, estando com os olhos voltados para os principais avanços nas Áreas das Ciências da Saúde, Humanas e Sociais. As demandas por publicações que causem impacto na comunidade científica nacional e internacional poderão ser alcançadas mediante um trabalho interdisciplinar árduo e interativo entre os diversos atores do processo de construção do conhecimento. Com este fim, o Programa se mobiliza a fim de proporcionar aos educandos um ensino de qualidade embasado na perspectiva ético-humanística, coerente com a missão da UCB de "atuar solidária e efetivamente para o desenvolvimento integral da pessoa humana e da sociedade, por meio da geração e comunhão do saber, comprometida com a qualidade, os valores éticos e cristãos, na busca da verdade”2. Sua Área de Concentração (Longevidade e Qualidade de Vida) busca ser integrativa, contemplando, ao mesmo tempo, a diversidade e a multidimensionalidade da velhice, abrindo espaço para estudos interdisciplinares. Para cumprir seus objetivos, o Mestrado em Gerontologia publicou uma coletânea de livros, com oito números já editados, que é um dos marcos que balizam a PPGG na UCB.

Para além de resposta regional, as especificidades do Programa o credenciam para se tornar uma alternativa nacional, devido à originalidade de suas duas Linhas de Pesquisa, sua perspectiva interdisciplinar e pelo zelo acadêmico na busca de soluções às questões dos idosos nos aspectos biopsicossociais.

Durante os 12 anos de funcionamento, o Programa em Gerontologia tem atendido a essa demanda regional, já que a maioria dos outros cursos na área do envelhecimento estão nas regiões Sul e Sudeste do país. A Gerontologia é um campo voltado à descrição das mudanças típicas do processo do envelhecimento e de seus determinantes genético-biológicos e psicossocioculturais. Além disso, estuda as características dos sujeitos idosos, bem como as diversificadas experiências da velhice e do envelhecimento que ocorrem em diferentes contextos. Ela estuda os aspectos do envelhecimento normal e patológico e busca compreender os diferentes níveis do desenvolvimento da vida, oferecendo teorias e modelos sobre o envelhecimento humano. Assim, o PPGG da UCB pretende aprofundar o conhecimento de forma interdisciplinar, por meio da pesquisa e da formação de recursos humanos, que venham contribuir para a elaboração de políticas públicas, serviços e informações nos âmbitos científico e tecnológico.

O objetivo desse texto foi o de investigar a produção científica desenvolvida no âmbito do referido PPGG em suas linhas de pesquisa, a partir das dissertações defendidas e das publicações dos docentes e discentes, que auxiliaram na construção do conhecimento na área da gerontologia.

\section{MÉTODOS}

Os dados foram obtidos mediante pesquisa documental, nos arquivos da Secretaria Acadêmica e nos dados anuais oficiais informados à CAPES, mediante o Coleta (até o ano de 2012) e a Plataforma Sucupira (a partir de 2013). Houve duas linhas 
de investigação, uma com os docentes e outra com os discentes. Para a pesquisa com os discentes (que inclui produção conjunta docente-discente), utilizouse o banco de dados online do Conselho Nacional de Desenvolvimento Científico e Tecnológico (CNPq) na Plataforma Lattes, inserindo-se o nome completo na opção "Buscar currículo" e no item "Produções". Buscou-se anotar apenas a produção bibliográfica, deixando para outra oportunidade as produções técnicas e artísticas. A intenção foi mostrar como se distribuiu, entre os diversos itens propostos pelo Lattes, a produção científica dos discentes a partir do ano em que concluíram seu curso com a defesa da dissertação e quais os resultados que foram dados a conhecimento na comunidade científica.

Para a pesquisa com os docentes, que também incluiu a produção docente-discente, consultou-se os dados divulgados pelo site oficial da Coordenação de Aperfeiçoamento de Pessoal de Nível Superior (CAPES), informados pelo Programa no Coleta (até o ano de 2012) ${ }^{3}$ e na Plataforma Sucupira (a partir de 2013) ${ }^{4}$. Optou-se por pesquisar apenas os dados da produção bibliográfica, nos seus diversos itens, sem levar em conta a classificação dada pela CAPES para o Qualis Periódicos, Qualis Livros ou Qualis Eventos.

Os dados encontrados foram lançados na planilha Excel para Windows 7 Professional, que gerou as diversas tabelas e cálculos dos resultados apresentados.

\section{RESULTADOS}

Com início do Programa na UCB em 2003, as primeiras 16 defesas de dissertações ocorreram em 2004 e 2005 (Figura 1), quando se oferecia 15 vagas anuais. A partir do reconhecimento do programa na CAPES em dezembro de 2004, passou-se a oferecer 15 vagas semestrais, possibilitando que ocorresse uma média de 19 defesas anuais, o que equivaleu a 63,3\% dos alunos ingressantes, ou seja, ao somar-se a evasão dos alunos com o número daqueles que não conseguiram defender no prazo de 24 meses, alcançou-se o percentual de $36,7 \%$, que está dentro da média esperada para os cursos de pós-graduação Stricto sensu, que é apontada pela CAPES como $50 \%$.

No período analisado foram defendidas 193 dissertações. A maioria das defesas ocorreu em 2009 $(16,06 \%)$, a seguir $2012(11,91 \%)$ e, com equidade, em 2006, 2010 e 2011 (9,84\%). A causa de número tão expressivo em 2009, deve-se às defesas de dissertações represadas nos anos anteriores, juntamente com a emergência de que ocorressem as defesas em razão do término daquele triênio (Figura 1). A média anual de 9,09\% foi suplantada nos anos finais dos triênios avaliativos (2012, 2006 e 2010), devido ao esforço que os orientadores realizaram para que se cumprisse o prazo de defesa estipulado pela CAPES.

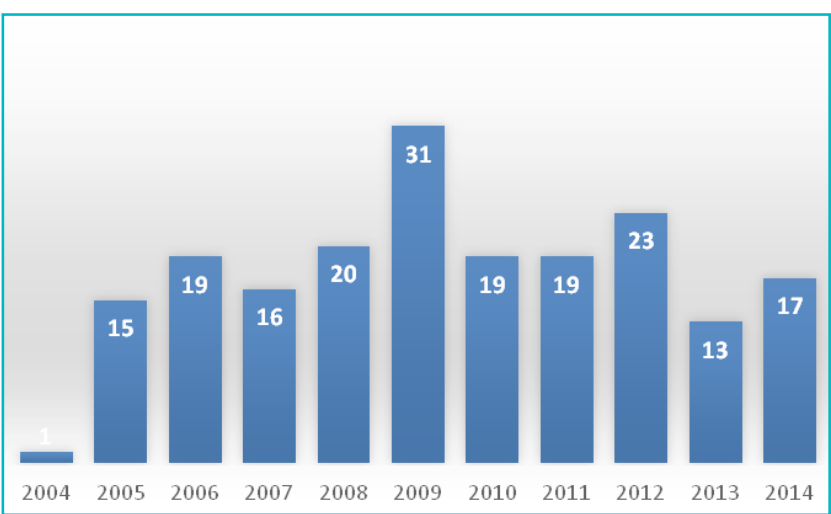

Figura 1. Número de dissertações defendidas entre 2004 e 2014

Levando em conta que o Programa contribui para a formação de futuros pesquisadores, e que um dos objetivos do curso é a produção de conhecimento científico, fez-se um levantamento das produções bibliográficas dos discentes (que inclui produção conjunta docente-discente) a partir do ano de defesa, conforme se mostra nas Figuras 2 e 3 e na Tabela 1 . Entre publicações em revistas, livros, capítulos e apresentação de trabalho, entre outras, totalizaram 1.102 produções bibliográficas, com média acima de 100 produções anuais. A maior média de produções por aluno ocorreu em 2006, com 11,78 por aluno, seguida do ano de 2009, com 9,93 por aluno. É preciso apontar algumas ressalvas com relação aos anos de 2004 e 2014. Em 2004, iniciaram-se as defesas, entretanto somente ocorreu uma única, fazendo com que a pontuação média de 9 produções por aluno seja muito alta, pois refere-se a essa única defesa. Em relação ao ano de 2014, a média de 0,70 é muito baixa, ocorrendo devido a não ter havido tempo hábil para a publicação de trabalhos científicos (dissertações totais ou suas partes), uma vez que entre defesa da dissertação, escrita do artigo, envio do texto a periódico e parecer conclusivo do mesmo e sua publicação, passa-se em média dois anos. Esse fato também pode ser observado no ano de 2013, no qual ainda poucas publicações se efetivaram. Nota-se que o número de alunos que não registraram suas produções na Plataforma Lattes ainda é alta (variação anual entre 1 a 10 alunos, com exclusão dos dois anos das extremidades, pelas razões acima citadas). Isto vai exigir por parte dos orientadores grande trabalho de conscientização da importância de informar os dados na referida Plataforma, na qual se oficializa as informações acadêmicas dos discentes e docentes. 


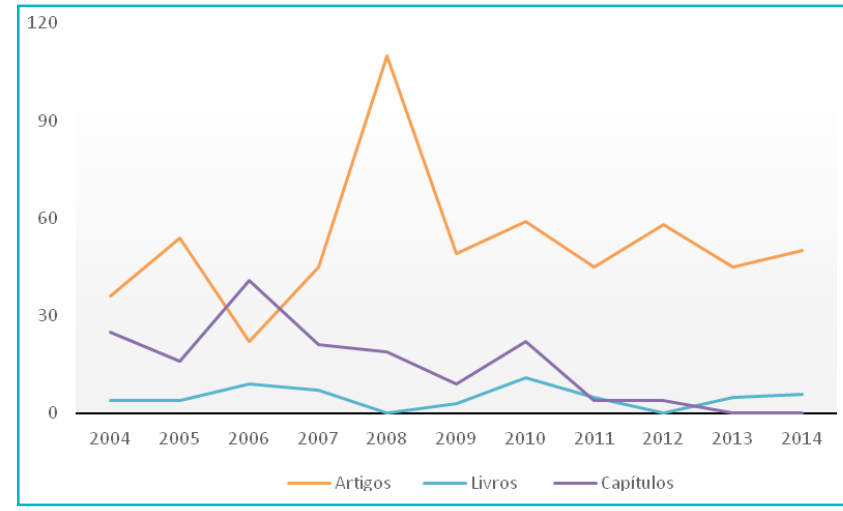

Figura 2. Artigos, livros e capítulos produzidos pelos discentes

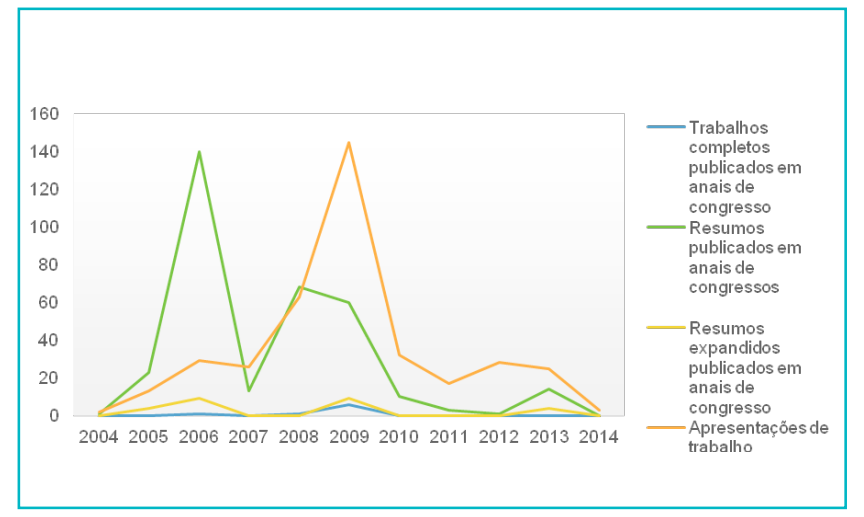

Figura 3. Trabalhos e produções em congressos e eventos pelos discentes

Tabela 1. Outras produções discentes

\begin{tabular}{lcccc|c|c|c|c|c|c|c}
\hline \multicolumn{1}{|c|}{ Ano } & $\mathbf{2 0 0 4}$ & $\mathbf{2 0 0 5}$ & $\mathbf{2 0 0 6}$ & $\mathbf{2 0 0 7}$ & $\mathbf{2 0 0 8}$ & $\mathbf{2 0 0 9}$ & $\mathbf{2 0 1 0}$ & $\mathbf{2 0 1 1}$ & $\mathbf{2 0 1 2}$ & $\mathbf{2 0 1 3}$ & $\mathbf{2 0 1 4}$ \\
\hline $\begin{array}{l}\text { Produção } \\
\begin{array}{l}\text { Textos em jornais de } \\
\text { notícias/revistas }\end{array}\end{array}$ & 0 & 3 & 4 & 1 & 2 & 2 & 6 & 6 & 1 & 0 & 0 \\
$\begin{array}{l}\text { Uutras produções } \\
\text { bibliográficas }\end{array}$ & 0 & 0 & 3 & 0 & 0 & 1 & 1 & 0 & 0 & 1 & 0 \\
$\begin{array}{l}\text { Artigos aceitos para } \\
\text { publicação }\end{array}$ & 0 & 0 & 0 & 1 & 1 & 6 & 1 & 2 & 5 & 1 & 9 \\
$\begin{array}{l}\text { Não há registro de } \\
\text { publicação no Lattes }\end{array}$ & 0 & 3 & 7 & 9 & 9 & 7 & 8 & 1 & 10 & 5 & 14 \\
\hline
\end{tabular}

Com relação à produção dos docentes, que inclui a produção conjunta docente-discente, encontrou-se dados significativamente mais elevados do que a dos discentes. A média de produção anual por docente foi feita com o número total de docentes, que abrange o núcleo permanente e os colaboradores, que é o conceito adotado pela CAPES para o termo "docente" Os resultados encontrados estão na Tabela 2. Foram 1.774 produções docentes, com média anual de 161 produções. As maiores médias de produção por docente ocorreram, em ordem decrescente, em 2008 (16,28), $2006(13,23)$ e 2007 (12,71). Ao registrar na Plataforma Lattes, os professores não anotaram nenhuma "Coletânea", apesar de o PPG ter uma coletânea de livros denominada "Redesenhando o envelhecimento" que, em 2014, chegou ao seu oitavo número. É possível que o uso dessa terminologia confunda mais do que esclareça, razão pela qual a CAPES, com a implantação da Plataforma Sucupira a partir de 2013, tenha realizado mudanças na classificação dos itens que eram considerados no Coleta (dados anteriores a 2012). Consideravam-se, até então, apenas três itens como produção bibliográfica: artigo em periódico, livro e trabalho em anais. O resumo de artigos também deixou de existir a partir da inserção da Plataforma Sucupira. A apresentação de trabalhos passou de produção técnica (antes de 2012) para produção bibliográfica (a partir de 2013).

A temática abordada nas dissertações abarca assuntos que abrangem sociedade, história e cultura, passando por prevalência de doenças crônico-degenerativas, epidemiologia, medicações e aposentadoria, até matéria da área de recursos humanos, o que preserva os objetivos interdisciplinares do PPG, conforme discutido por Mendes et al. ${ }^{7}$

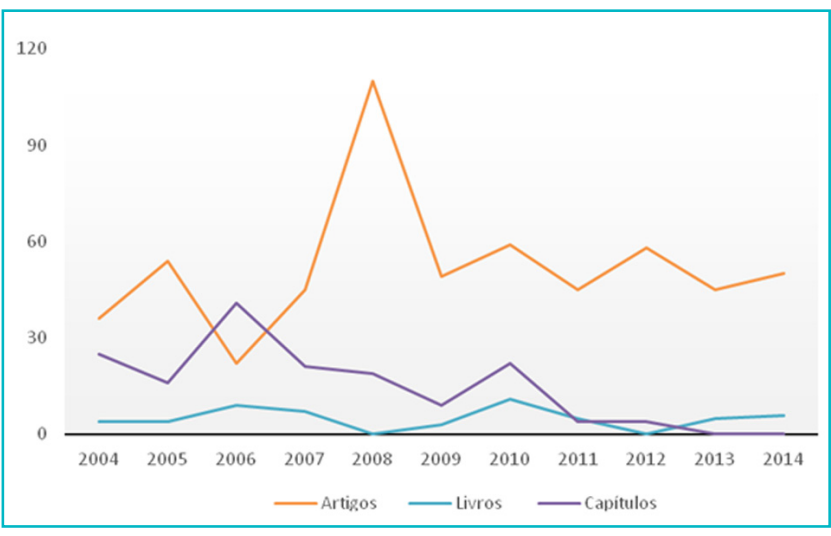

Figura 4. Principais produções dos Docentes 
Tabela 2. Outras Produções bibliográficas dos docentes

\begin{tabular}{|c|c|c|c|c|c|c|c|c|c|c|c|}
\hline Produção $\quad$ Ano & 2004 & 2005 & 2006 & 2007 & 2008 & 2009 & 2010 & 2011 & 2012 & 2013 & 2014 \\
\hline $\begin{array}{l}\text { Trabalhos completos } \\
\text { publicados em anais de } \\
\text { congresso }\end{array}$ & 7 & 9 & 63 & 40 & 46 & 32 & 6 & 18 & 27 & 51 & 18 \\
\hline $\begin{array}{l}\text { Artigos } \\
\text { Resumo }\end{array}$ & 13 & 30 & 9 & 0 & 0 & 0 & 0 & 0 & 0 & 0 & 0 \\
\hline $\begin{array}{l}\text { Resumos anais } \\
\text { publicados em de } \\
\text { congresso }\end{array}$ & 83 & 57 & 90 & 42 & 41 & 11 & 3 & 2 & 26 & 0 & 0 \\
\hline Coletânea & 3 & 0 & 0 & 0 & 0 & 0 & 0 & 0 & 0 & 0 & 0 \\
\hline $\begin{array}{l}\text { Apresentações de } \\
\text { trabalho }\end{array}$ & 4 & 34 & 44 & 23 & 12 & 33 & 20 & 12 & 17 & 40 & 20 \\
\hline
\end{tabular}

Tabela 3. Total de produções e médias por docente

\begin{tabular}{|c|c|c|c|c|c|c|c|c|c|c|c|}
\hline Ano & 2004 & 2005 & 2006 & 2007 & 2008 & 2009 & 2010 & 2011 & 2012 & 2013 & 2014 \\
\hline Produção Total & 175 & 204 & 278 & 178 & 228 & 137 & 121 & 86 & 132 & 141 & 94 \\
\hline $\begin{array}{l}\text { Média } \\
\text { Produção por docente }\end{array}$ & 10,93 & 8,16 & 13,23 & 12,71 & 16,28 & 9,78 & 7,56 & 5,37 & 8,25 & 9,4 & 6,26 \\
\hline
\end{tabular}

\section{DISCUSSÃO}

Já em 2002, Goldstein ${ }^{8}$ relatou o início da produção científica brasileira na área da Gerontologia. A partir de 1975, até 1999, haviam 232 trabalhos científicos, sendo 188 dissertações de mestrado, 39 teses de doutorado e cinco teses de livre docência, além de três teses de doutorado e duas dissertações de mestrado realizadas por brasileiros em Universidades estrangeiras. Demorou-se 24 anos para produzir 188 dissertações nesses anos iniciais da Gerontologia no Brasil, enquanto que o PPGG da UCB levou 11 anos para alcançar 193 dissertações. Embora os momentos históricos são diferentes, mas não deixa de ser recompensador verificar que o trabalho dos pioneiros rendeu muitos frutos e se multiplicou em nosso solo pátrio.

A mesma comprovação foi descrita Jerez-Roig et al. ${ }^{9}$, que constataram crescimento do número de trabalhos publicados na Revista Brasileira de Geriatria e Gerontologia (RBGG) no período 20062013, com temática abordando, em maior número, aspectos psicológicos, atividade física e nutrição no envelhecimento. A RBGG é revista de referência na área, sendo que nos sete anos de levantamento feito pelos autores, teve pelo menos 10 publicações do PPGG da UCB, abrangendo docentes e discentes, entre os 400 trabalhos do período analisado, como artigos originais $(75,3 \%)$ ou revisões 42 (10,5\%).
Prado e Sayd ${ }^{10}$ relataram que houve grande esforço dos pesquisadores da área de Gerontologia para produzirem conhecimento autóctone em parceria com pesquisadores estrangeiros, o que contribuiu para a legitimação da área da Gerontologia entre as áreas de conhecimento, constituindo-a como autoridade que se apoia no conhecimento científico. A produção do PPGG da UCB, junto com as demais instituições de ensino superior que possuem Programas de PósGraduação Stricto sensu na área, tem ajudado nesse processo construtivo da Gerontologia no Brasil.

\section{CONCLUSÕES}

O PPGG da UCB apresentou número significativo de produções científicas durante seus 12 anos de existência. $O$ conjunto dessas publicações mostra que há muito ainda a ser investido na busca de conhecimentos novos na área. O esforço contínuo deve ser realizado pelos docentes, incentivando os discentes a publicar seus trabalhos de pesquisa e dissertações, promovendo cada vez mais a interdisciplinaridade. Ao mesmo tempo, o empenho redobrado deve ser efetivo, para que se atinja cada vez maior qualidade das publicações, divulgando-as em periódicos de nível A no Qualis CAPES. Com o número crescente da população idosa no país, acredita-se que haja necessidade de multiplicação do conhecimento gerontológico. Desta forma, o PPGG da UCB pretende contribuir 
significativamente com a expansão do conhecimento na área da Gerontologia no Brasil, permitindo que ela seja cada vez mais reconhecida na comunidade científica.

\section{REFERÊNCIAS}

1. Universidade Católica de Brasília (UCB), 2015. Áreas de concentração e linhas de pesquisa [acesso 26 maio 2015]. Disponível em http://www.ucb.br/textos/2/433/AreaDeConce ntracaoELinhasDePesquisa/?slT =8

2. Universidade Católica de Brasília (UCB), 2015. Missão e Visão. Disponível em http://www.ucb.br/textos/2/1308/ MissaoEVisao/ Acesso em 26 mai 2015.

3. CAPES, Caderno de Indicadores. Mestrados/Doutorados Reconhecidos por Programas e IES [acesso 17 maio 2015]. Disponível em: http://conteudoweb.capes.gov.br/conteudoweb/ ProjetoRelacaoCursosServlet? codigoPrograma $=53003012009$ $\mathrm{PO} \&$ acao $=$ detalhamentoPrograma\&siglaIes $=U C B \#$

4. CAPES, Plataforma Sucupira. Consultas públicas [acesso 17 maio 2015]. Disponível em: https://sucupira.capes.gov. br/sucupira/public/consultas/coleta/producaoIntelectual/ listaProducaoIntelectual.jsf

5. CAPES. III PNPG - Plano Nacional de Pós-Graduação [acesso 17 maio 2015]. Disponível em: https://www.capes. gov.br/images/stories/download/editais/III_PNPG.pdf
6. Portaria 174/2014, que define as Categorias Docentes dos Programas de Pós Graduação - CAPES [acesso 17 maio 2015]. Disponível em: http://www.capes.gov.br/images/ stories/download/legislacao/PORTARIA-N-174-DE-30-122014.pdf

7. Mendes GS, Valadares MO, Gomes LV, Alves VP. Interdisciplinaridade na primeira década do programa de Pós-Graduação Stricto Sensu em Gerontologia de Brasília (DF). Revista Kairós. 2014;17(2) [acesso 17 maio 2015]. Disponível em: http://revistas.pucsp.br/index.php/kairos/ article/view/21277/15555

8. Goldstein LL. A Produção Científica Brasileira na Área da Gerontologia. 10/09/2002. Rev. Online Bibl. Prof. Joel Martins, 2(1). [acesso 26 maio 2015]. Disponível em: http://www.brapci.ufpr.br/documento. php?dd $=0000003505 \&$ dd $1=$ debfc

9. Jerez-Roig J, Guedes MBOG, Dias e Silva JM, Lima KC. Análise da produção científica da Revista Brasileira de Geriatria e Gerontologia: uma revisão bibliométrica. Revista Brasileira de Geriatria e Gerontologia [acesso 26 maio 2015]. Disponível em: http://www.scielo.br/pdf/rbgg/v17n3/1809. 9823-rbgg-17-03-00659.pdf

10 Prado SD, Sayd JD. A gerontologia como campo do conhecimento científico: conceito, interesses e projeto político. Revista Ciênc. Saúde coletiva. 2006 Jun;11(2): 491-501 [acesso 26 maio 2015]. Disponível em: http:// www.scielo.br/scielo.php?script $=$ sci_arttext $\&$ pid $=$ S1413 $81232006000200026 \& \operatorname{lng}=$ en 